\title{
Karakteristik Himpunan Kritis dalam Pelabelan TSA pada Graf Pohon
}

\author{
Triyani ${ }^{1}$, Siti Rahmah Nurshiami1 ${ }^{2}$, Ari Wardayani ${ }^{3}$, Irham Taufiq ${ }^{4}$ \\ 1,2,3Jurusan Matematika FMIPA Universitas Jenderal Soedirman \\ ${ }^{4}$ Jurusan Pendidikan Matematika FKIP Universitas Sarjanawiyata \\ Tamansiswa \\ Email: trianisr@yahoo.com.au, nurshiami@yahoo.co.id, ariwardayani@yahoo.co.id, \\ irham.taufiq@gmail.com
}

\begin{abstract}
ABSTRAK
Sebuah himpunan kritis dalam pelabelan Total Sisi Ajaib (TSA), $\lambda$ pada graf $G$ adalah subhimpunan label sedemikian sehingga label tersebut membangun pelabelan TSA secara tunggal. Konsep himpunan kritis pada pelabelan graf ini merupakan pengembangan teori dari himpunan kritis dalam bujur sangkar latin yang dikemukakan oleh Cooper dkk (1994). Artikel ini bertujuan menginvestigasi karakteristik himpunan kritis dalam pelabelan TSA pada graf pohon. Hasil penelitian menunjukkan bahwa jika $G$ adalah graf pohon, maka himpunan kritis dengan ukuran minimal dalam pelabelan TSA pada $G$ sama dengan banyaknya daun di $G$.
\end{abstract}

Kata Kunci : himpunan kritis minimal, pelabelan TSA, graf TSA

\section{ABSTRACT}

A critical set in edge magic total (EMT) labeling $\lambda$ on graph $G$ is a subset label such that it can forms the EMT labeling uniquely. The concept of a critical set on this graph labeling is the development of the critical set theory in latin squares proposed by Cooper et al (1994). This article aims to investigate some of the characteristics of critical set in TSA labeling on tree. The result showed that if $G$ is tree, then the critical set of a minimum size in EMT labeling on $G$ equals the number of leaf in $G$.

Key words : minimum critical set, EMT labeling, tree, number of leaf.

\section{Pendahuluan}

Himpunan kritis merupakan suatu informasi parsial dari suatu himpunan, sedemikian sehingga dengan mengetahui informasi parsial ini, dapat direkonstruksi himpunan lain secara tunggal. Ide dasar himpunan kritis ini adalah bujur sangkar latin, yaitu matriks berukuran $n$ $\times n$ dengan elemen-elemennya dipilih dari himpunan bilangan bulat positif $1,2,3, \ldots n$. Setiap bilangan ini terdapat pada setiap baris dan kolom sedemikian sehingga tidak ada baris atau kolom yang mempunyai bilangan yang sama (Cooper, dkk., 1994).

Berdasarkan pengertian himpunan kritis ini, Baskoro(2005) mendefinisikan himpunan kritis pada pelabelan graf sebagai suatu sub himpunan label titik dan sisi pada graf yang dapat membangun pelabelan graf secara tunggal. Pelabelan graf secara umum didefinisikan sebagai suatu pemetaan yang mengaitkan elemen dari graf baik berupa titik, sisi, maupun titik dan sisi ke bilangan-bilangan bulat positif yang selanjutnya disebut label. Penentuan masalah apakah suatu sub himpunan label pada elemen-elemen di graf adalah himpunan kritis atau bukan, merupakan suatu masalah yang tidak mudah, karena harus memeriksa semua kemungkinan dari sub himpunan label tersebut apakah sub himpunan tersebut hanya dapat membangun sebuah pelabelan graf secara tunggal. 
Suatu pelabelan graf disebut pelabelan Total Sisi Ajaib (TSA) jika jumlah label sisi dan dua label titik yang insiden dengannya sama untuk setiap sisi di graf tersebut. Tidak semua graf dapat dilabeli dengan pelabelan TSA. Graf yang dapat dilabeli dengan pelabelan TSA disebut graf TSA. Konjektur Enomoto, et all (1998) menyatakan bahwa graf pohon adalah graf TSA. Dalam jurnal elektronik tentang pelabelan graf, Galian (2007) telah menguraikan beberapa graf yang termasuk graf TSA diantaranya graf lintasan, graf gabungan lintasan dan graf sikel.

Baskoro (2005) telah memperoleh himpunan kritis dalam pelabelan Total Sisi Ajaib (TSA) pada graf Star, Disjoint Star dan graf lengkap $K_{n}, n=1,2, \ldots, 6$. Selanjutnya Baskoro, dkk mengaplikasikan himpunan kritis ini dalam Skema Pembagian Rahasia (Secret Sharing Schemes) yaitu suatu metode untuk membagi suatu kunci rahasia kepada sejumlah partisipan sedemikian sehingga hanya partisipan tertentu saja yang dapat merekonstruksi kunci rahasia tersebut. Kunci rahasia ini dapat direkonstruksi dengan cara mengumpulkan semua informasi parsial dari masing-masing partisipan yang diberi wewenang.

Imron, dkk (2007) telah memperoleh himpunan kritis dalam pelabelan TSA pada graf Caterpillar dan mengaplikasikan himpunan kritis dalam pelabelan ajaib ini untuk keperluan pembatalan transaksi di suatu supermarket. Triyani, dkk (2013) telah memperoleh himpunan kritis dalam pelabelan TSA pada graf Caterpilar Teratur serta mengimplementasikan himpunan kritis ini pada sistem pengamanan informasi akademik.

Secara teori dari beberapa hasil penelitian, masih sedikit penelitian tentang karakteristik dari himpunan kritis dalam pelabelan graf. Oleh karena itu pada artikel ini diuraikan karakteristik himpunan kritis dalam pelabelan TSA pada graf pohon khususnya graf Star, Caterpillar, Banana Tree dan Firecracker.

\section{Pelabelan Total Sisi Ajaib Dan Himpunan Kritis Pada Pelabelan Graf}

Pelabelan Total Sisi Ajaib (TSA) dari suatu graf $G(V, E)$ dengan $V$ himpunan titik dan $E$ himpunan sisi adalah suatu fungsi bijektif yang memetakan himpunan titik dan sisi ke himpunan bilangan bulat positif $1,2, \ldots,|V|+|E|$ sedemikian sehingga jumlah bobot total sisi yaitu jumlah label sebuah sisi dengan bobot dua titik yang insiden dengan sisi tersebut sama. Lebih lanjut jika setiap titik di G dilabeli dengan bilangan terurut $1,2, \ldots,|V|$, maka dikataklan G mempunyai pelabelan Total Super Sisi Ajaiab (TSSA). Pelabelan ini dikatakan pelabelan total karena semua sisi dan titik di graf G diberi label dan dikatakan sisi ajaib karena untuk setiap sisi di graf $\mathrm{G}$, bobot total setiap sisi di G sama adalah konstanta $c$. Konstanta $c$ ini selanjutnya disebut konstanta ajaib untuk graf G. Tidak semua graf mempunyai pelabelan TSA. Graf yang mempunyai pelabelan TSA disebut graf TSA.

Dalam jurnal elektronik tentang pelabelan graf, Galian (2007) juga telah menguraikan beberapa hasil dari jenis pelabelan TSA pada beberapa kelas graf, seperti graf Lintasan $P_{\mathrm{n}}$, graf Sikel $C_{\mathrm{n}}$, untuk $\mathrm{n} \geq 3$, Graf Lengkap $K_{\mathrm{n}}$, untuk $n=1,2, \ldots, 6$; Graf Lengkap Bipartit, $K_{\mathrm{m}, \mathrm{n}}$; Graf Roda $W_{\mathrm{n}}$, untuk $n \neq 3(\bmod 4)$, Graf Kipas $F_{n}$ dan lain sebaginya.

Berikut diberikan teorema dan lemma yang telah dihasilkan berkaitan dengan pelabelan graf khususnya pelabelan Total Sisi Ajaib.

Teorema 1. (Baskoro, dkk, 2005). Konstanta ajaib $c$ pada pelabelan TSA graf pohon dengan $p$ titik adalah $2 p+2 \leq c \leq 4 p-2$.

Teorema 2. (Baskoro, dkk, 2005). Graf Star Sn adalah graf TSA dengan memberi label pada titik pusatnya dengan $1, n+1$ atau $2 n+1$. 
Teorema 3. (Hussain, dkk. 2009). Graf Banana Tree $\operatorname{BT}\left(n_{1}, n_{2}, \ldots, n_{\mathrm{k}}\right)$ dengan $n 1=n_{2}=\ldots=$ $n_{\mathrm{k}}=n$ adalah Graf TSSA.

Teorema 4. (Triyani, dkk, 2015) Jika $\lambda$ menyatakan pelabelan TSSA, maka konstanta ajaib untuk pelabelan $\lambda$ pada graf Firecracker $F_{n, k}$ adalah $c=\frac{1}{2}(5 n-1) k+2$, untuk $n$ ganjil dan $c=$ $\frac{5}{2} n k+1$, untuk $n$ genap.

Menurut Baskoro, dkk (2005) sebuah himpunan kritis pada graf $G$ dengan pelabelan $\lambda$ adalah himpunan $Q_{\lambda}(G)=\{(a, b) \mid a, b \in\{1,2, \ldots,|V(G) \cup E(G)|\}\}$, dengan $(a, b)$ adalah pasangan terurut yang menyatakan label $b$ pada posisi $a$, di mana:

a) $\quad \lambda$ adalah satu-satunya pelabelan pada $G$ dengan label $b$ pada posisi $a$ yang dapat direkonstruksi dari $Q_{\lambda}(G)$.

b) Setiap sub himpunan dari $Q_{\lambda}(G)$ tidak memenuhi sifat (a).

Berkaitan dengan himpunan kritis pada pelabelan TSA, berikut diberikan beberapa teorema yang telah dihasilkan oleh Baskoro dkk (2005).

Teorema 5. Misal $Q=\left\{a_{1}, a_{2}, \ldots, a_{\mathrm{q}}\right\}$ adalah himpunan kritis dari pelabelan TSA $\lambda$ pada graf G dengan $n$ titik dan $m$ sisi. Maka $Q^{\prime}=\left\{M-a_{1}, M-a_{2}, \ldots, M-a_{\mathrm{q}}\right\}$ adalah himpunan kritis dari pelabelan dual $\lambda^{\prime}$ pada $G$ dengan $M=n+m+1$.

Teorema 6. Misalkan $\lambda$ adalah pelabelan TSA pada graf bintang $S_{n}$ dengan $n$ titik. Maka, ukuran dari himpunan kritis dalam pelabelan $\lambda$ adalah $n-1$ atau $n$.

Akibat 1. Jika $Q_{\lambda}$ adalah himpunan kritis dalam pelabelan TSA $\lambda$ pada graf Star $\mathrm{S}_{\mathrm{n}}$ dengan $n$ titik, dan c adalah titik pusat dari graf Star, maka diperoleh akibat sebagai berikut:

1. Hanya $\mathrm{Q}_{\lambda}=\{1,2,4, \ldots, 2 \mathrm{n}-2\}$ dan $\mathrm{Q}_{\lambda}=\{1, n+1, n+2, \ldots, 2 n-1\}$ yang merupakan himpunan kritis dengan ukuran $n$ jika $\lambda(\mathrm{c})=1$;

2. Hanya $\mathrm{Q}_{\lambda}=\{1,2,3, \ldots, n\}$ dan $\mathrm{Q}_{\lambda}=\{n, n+1, n+2, \ldots, 2 n-1\}$ yang merupakan himpunan kritis dengan ukuran $n$ jika $\lambda(c)=n$;

3. Hanya $Q_{\lambda}=\{1,2, \ldots, n-1,2 n-1\}$ dan $Q_{\lambda}=\{2,4, \ldots, 2 n-2,2 n-1\}$ yang merupakan himpunan kritis dengan ukuran $n$ jika $\lambda(c)=2 n-1$.

Teorema 7. Untuk setiap pelabelan TSA pada Graf Star $\mathrm{S}_{n}$ dengan $n$ titik terdapat dua himpunan kritis $\lambda$ dengan ukuran $n$ dan $2^{n-1}-2$ himpunan kritis dengan ukuran $n-1$.

\section{Karakteristik Himpunan Kritis Pada Pelabelan Tsa Untuk Graf Pohon}

Telah diketahui bahwa graf Caterpillar, Firecracker dan Banana Tree adalah graf - graf Total Sisi Ajaib. Berikut diberikan contoh pelabelan TSA $\lambda$ untuk graf Firecarcker $F_{4,4}$ dengan konstanta ajaib $c=41$. 


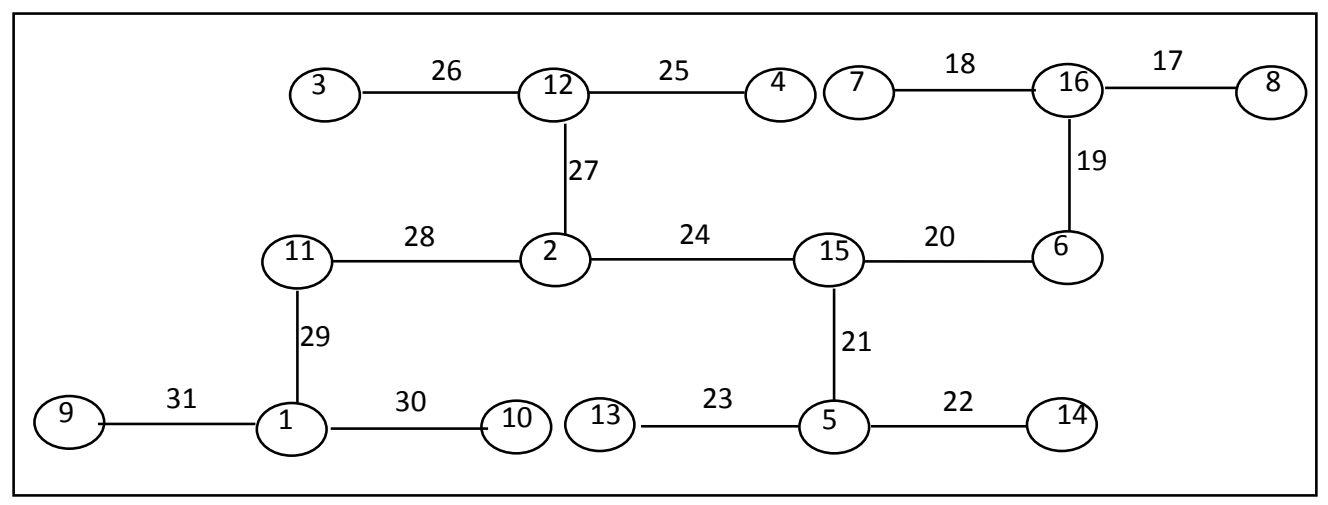

Gambar 1 Pelabelan TSA $\lambda$ pada graf Firecracker $F_{4,4}$ dengan $c=41$

Berdasarkan formula pelabelan TSA dan semua kemungkinan himpunan kritis dalam pelabelan TSA pada graf-graf TSA, diperoleh karakteristik himpunan kritis dalam pelabelan TSA yang dituangkan dalam teorema dan lemma sebagai berikut

Teorema 8. Jika $G$ adalah graf pohon, maka himpunan kritis minimal dalam pelabelan TSA pada $G$ adalah sebanyak daunnya.

Bukti. Diberikan $G$ adalah graf pohon, $\lambda$ adalah pelabelan TSA pada $G$ dan $Q_{\lambda}(G)$ adalah himpunan kritis pada $G$. Misalkan pula $x_{\mathrm{i}}$ menyatakan label daun ke- $i$ dan $y_{\mathrm{i}}$ menyatakan label sisi yang berinsiden dengan daun ke- $i$ pada graf $G$ yang bersisian dengan $x_{\text {i. }}$ Notasi $\left(a, x_{i}\right)$ menyatakan label $x_{\text {i }}$ pada posisi $a$ dan $\left(b, y_{i}\right)$ menyatakan label $y_{i}$ pada posisi $b$. Andaikan kardinalitas $Q_{\lambda}(G)$ kurang dari jumlah daunnya. Akibatnya adalah terdapat suatu daun pada posisi $c$ dengan label $x_{\mathrm{i}}$, yaitu (c, $\left.x_{\mathrm{i}}\right)$ dan sisi yang berinsiden dengan daun pada posisi $d$ dengan label $y_{\mathrm{i}}$ yaitu $\left(d, y_{\mathrm{i}}\right)$ yang bersisian keduanya tidak berada di $Q_{\lambda}(G)$. Oleh karena itu dapat dikonstruksi pelabelan total sisi ajaib selain $\lambda$ dengan cara menukar pasangan terurut $\left(c, x_{i}\right)$ dengan $\left(c, y_{\mathrm{i}}\right)$ dan $\left(d, y_{\mathrm{i}}\right)$ dengan $\left(d, x_{\mathrm{i}}\right)$. Hal ini kontradiksi dengan definisi himpunan kritis. Oleh karena itu haruslah himpunan kritis dari $G$ lebih dari sama dengan jumlah daunnya.

Sebagai ilustrasi dari teorema ini, berikut diberikan sebuah himpunan $\left\{(a, b) \mid(a, b) \in\left\{1,2, \ldots,\left|V\left(F_{4,4}\right) \cup E\left(F_{4,4}\right)\right|\right\}\right.$, dengan $(a, b)$ adalah pasangan terurut yang menyatakan label $b$ pada posisi a.Pelabelan TSA diberikan pada Gambar 1 dan label posisi diberikan pada Gambar 2 berikut.

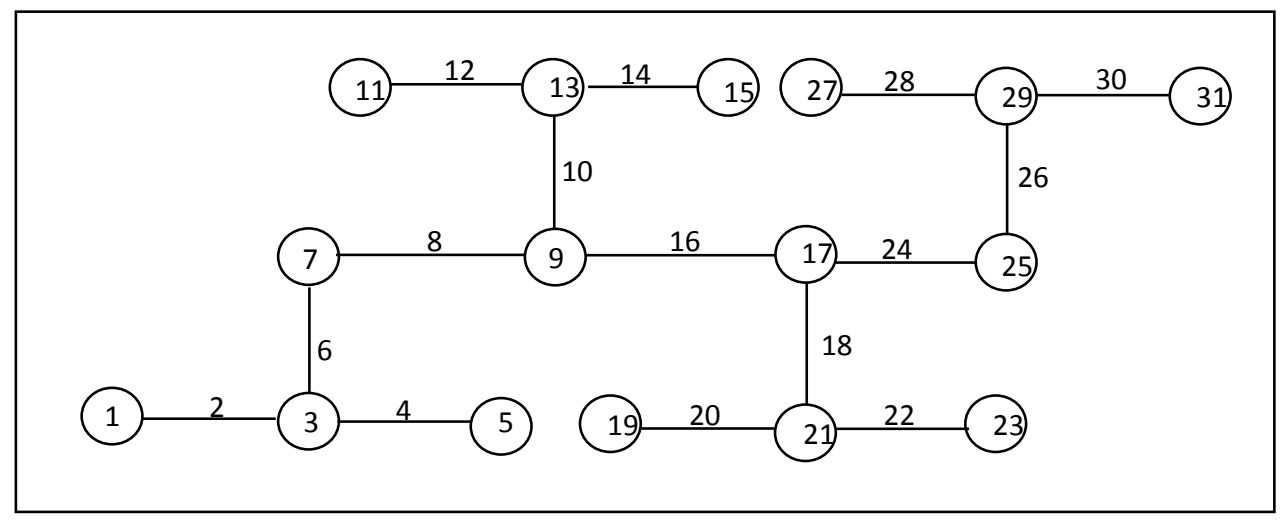

Gambar 2 Label posisi pada graf Firecracker $F_{4,4}$ 
Misal diberikan

$Q_{\lambda}\left(F_{4,4}\right)=\{(1,9),(5,10),(11,3),(15,4),(19,13),(23,14),(27,7),(31,8)\}$.

$Q_{\lambda}\left(F_{4,4}\right)$ merupakan himpunan kritis minimal, karena jika diambil sebuah anggota dari $Q_{\lambda}\left(F_{4,4}\right)$, maka dapat dikonstruksi pelabelan TSA selain pelabelan pada Gambar 1. Tanpa mengurangi keumuman, ambil pasangan $(1,9)$ dari $Q_{\lambda}\left(F_{4,4}\right)$. Akibatnya diperoleh pelabelan selain pelabelan pada Gambar 1 . dengan menukar $(1,9)$ dengan $(1,31)$ dan $(2,31)$ dengan $(2,9)$. Pelabelan TSA yang baru diilustrasikan pada Gambar 3 sebagai berikut.

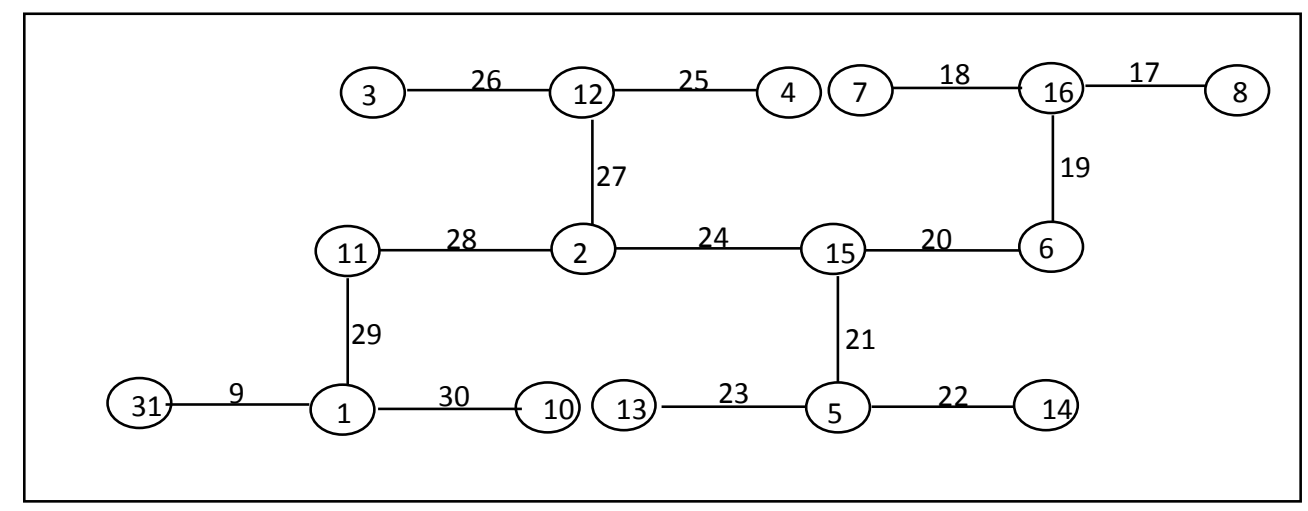

Gambar 3 Pelabelan TSA $\lambda_{2}$ graf Firecracker $F_{4,4}$

Akibat 1. Jika $F_{n, k}$ adalah graf Firecracker teratur dengan $k$ menyatakan banyaknya titik pada graf bintang dan $n$ menyatakan banyaknya graf bintang, maka himpunan kritis minimal graf $F_{n, k}$ berukuran $n(k-2)$.

Bukti. Diketahui $\lambda\left(F_{n, k}\right)$ adalah pelabelan total sisi ajaib pada graf $F_{n, k}$ dan $Q_{\lambda}\left(F_{n, k}\right)$ adalah himpunan kritis pada $\lambda\left(F_{n, k}\right)$. Misal $x_{i}$ menyatakan label daun ke- $i$ dan $y_{i}$ menyatakan label sisi yang berinsiden dengan daun ke- $i$ pada graf $F_{n, k}$ yang bersisian dengan $x_{i}$ dengan $i=1,2, \ldots, n(k-2)$. Selanjutnya, $\left(a, x_{i}\right)$ menyatakan label $x_{i}$ pada posisi $a$ dan $\left(b, y_{i}\right)$ menyatakan label $y_{i}$ pada posisi $b$. Akan ditunjukkan bahwa himpunan kritis pada graf $F_{n, k}$, minimal berukuran $n(k-2)$. Andaikan $\left|Q_{\lambda}\left(F_{m, k}\right)\right|<n(k-2)$, artinya banyaknya elemen dari himpunan kritis pada graf $F_{n, k}$ kurang dari jumlah daunnya.Akibatnya terdapat suatu daunpada posisi $c$ dengan label $x_{i}$ yaitu $\left(c, x_{i}\right)$ dan sisi yang berinsiden dengan daunpada posisi $d$ dengan label $y_{i}$ yaitu $\left(d, y_{i}\right)$ yang bersisian keduanya tidak berada di $Q_{\lambda}\left(F_{n, k}\right)$. Oleh karena itu dapat dikonstruksi pelabelan total sisi ajaib selain $\lambda\left(F_{n, k}\right)$ dengan cara menukar pasangan terurut $\left(c, x_{i}\right)$ dengan $\left(c, y_{i}\right)$ dan $\left(d, y_{i}\right)$ dengan $\left(d, x_{i}\right)$. Hal ini dikontradiksi dengan definisi himpunan kritis. Oleh karena itu haruslah $\left|Q_{k}\left(F_{n k}\right)\right| \geq n(k-2)$.

Akibat 2. Jika $B_{k_{1}, k_{2}, \ldots, k_{n}}$ dengan $k_{1}=k_{2}=\ldots=k_{n}=k, k \geq 2$, menyatakan graf Banana Tree Teratur, maka himpunan kritis minimal pada $B_{k_{1}, k_{2}, \ldots, k_{n}}$ berukuran $n(k-2)$. 
Bukti. Graf Banana Tree Teratur $B_{k_{1}, k_{2}, \ldots, k_{n}}$ untuk $k_{1}=k_{2}=\ldots=k_{n}=k, k \geq 2$ mempunyai titik sebanyak

$$
\begin{aligned}
\left|V\left(B_{k_{1}, k_{2}, \ldots, k_{n}}\right)\right| & =1+\left|V\left(S_{k_{1}}\right)\right|+\left|V\left(S_{k_{2}}\right)\right|+\ldots+\left|V\left(S_{k_{n}}\right)\right| \\
& =1+n k
\end{aligned}
$$

Graf Banana Tree Teratur merupakan graf pohon, sehingga banyak sisinya ada $\left|E\left(B_{k_{1}, k_{2}, \ldots, k_{n}}\right)\right|=n k$. Karena graf Banana Tree teratur dibentuk dari graf Star $S_{k}$, dengan menggabungkan sebuah daunnya dengan sebuah titik baru, maka banyaknya daun ada $n(k-2)$

Akibat 3. Jika $S_{n}$ adalah graf Star dengan $n$ titik, maka himpunan kritis minimal pada $S_{n}$ berukuran $n-1$.

Bukti. Analog dengan lemma 1., Graf Star $S_{n}$ mempunyai $n$ titik dengan satu titik sebagai titik pusat berderajat $(n-1)$ dan $(n-1)$ daun dengan derajat setiap daunnya adalah satu

Akibat 4. Jika $C_{k_{1} k_{2} \ldots k_{n}}$ menyatakan graf Caterpillar, maka himpunan kritis minimal pada $C_{k_{1} k_{2} \ldots k_{n}}$ berukuran $\left(k_{1}+k_{2}+\ldots+k_{n}\right)-n$.

Bukti. Analog dengan lemma 1.,graf $C_{k_{1} k_{2} \ldots k_{n}}$ merupakan graf gabungan dari graf star $S_{k_{i}}, i=$ $1,2, \ldots, n$ yang setiap titik pusat graf $\operatorname{Star} S_{k_{i}}$ dihubungkan dengan titik pusat graf $\operatorname{Star} S_{k_{i+1}}$ untuk $i=1,2, \ldots, n-1$. Akibatnya banyaknya daun graf Caterpillar $C_{k_{1} k_{2} \ldots k_{n}}$ sama dengan $\left(k_{1}+k_{2}+\ldots+k_{n}\right)-n$

Akibat 5. Jika $\lambda(x)$ adalah label dari daun $x$ dan $\lambda(y)$ adalah label dari sisi yang bersisian dengan titik/daun $x$, maka setiap himpunan kritis minimal dalam $\lambda$ harus memuat $\lambda(x)$ atau $\lambda(y)$, tetapi tidak keduanya.

Akibat 6. Label dari semua sisi yang berinsiden dengan daun bukan merupakan himpunan kritis.

Pasangan terurut dari posisi label (Gambar 2) dan pelabelan TSA pada Gambar 1 dengan label semua sisi yang berinsiden dengan daun yaitu $\{(2,31),(4,30),(12,26),(14,25),(20,23),(22,22),(28,18),(30,17)\}$ bukan merupakan himpunan kritis dalam pelabelan TSA pada graf $F_{4,4}$, karena dari himpunan ini dapat dikonstruksi pelabelan TSA $\lambda_{3}$ selain pelabelan pada Gambar 1. Pelabelan TSA $\lambda_{3}$ dapat dilihat pada Gambar 4 sebagai berikut. 


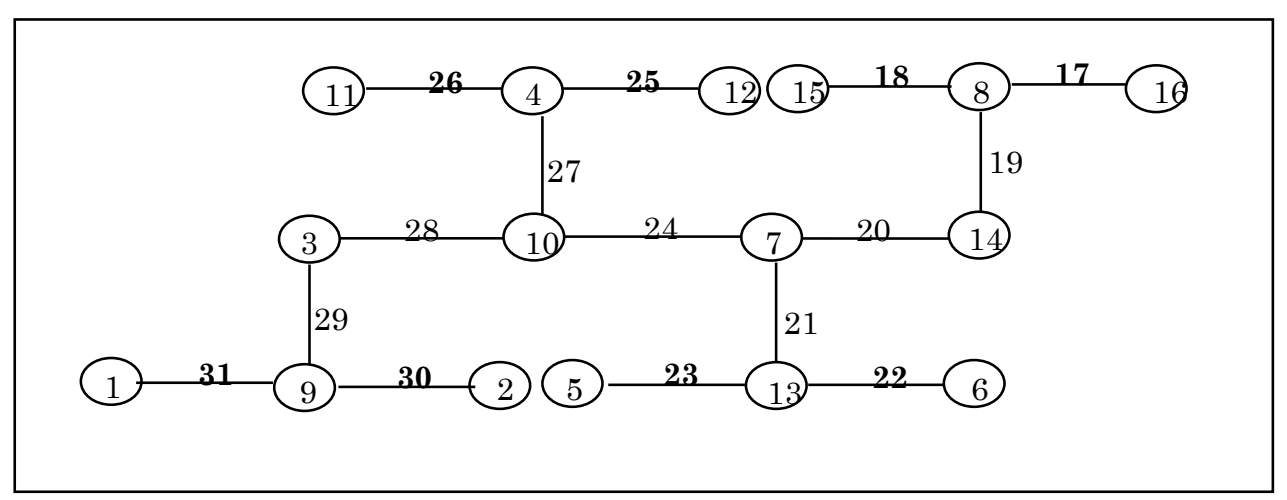

Gambar 4 Pelabelan TSA $\lambda_{3}$ pada graf $F_{4,4}$

\section{Kesimpulan}

Beberapa kesimpulan yang dihasilkan pada penelitian ini adalah bahwa Graf Star, Caterppilar, Banana Tree dan Firecracker merupakan graf TSA. Himpunan kritis minimal pada graf pohon adalah sejumlah daunnya. Setiap himpunan kritis dalam pelabelan TSA pada graf pohon harus memuat label daun atau label sisi yang berinsiden dengan daun yang bersisian dengannya, tetapi tidak boleh memuat keduanya sekaligus. Label dari semua sisi yang berinsiden dengan daun bukan merupakan himpunan kritis.

\section{Daftar Pustaka}

1. Baskoro, E.T., Rinovia S. \& Mariskha T. A. 2004. Secret Sharing Scheme Based On Magic Labeling. Department of Mathematics. ITB Bandung.

2. Baskoro, E.T., 2005. Critical sets in Edge Magic Total Labellings. Department of Mathematics. ITB Bandung.

3. Cooper, J., D. Donovan and J. Seberry. 1994. Secret Sharing Scheme Arising from Latin Square. Bulletin of the ICA. p33-43.

4. Enomoto, H., A.S.Llado, T. Nakamigawa, and G. Ringel. 1998. Super Edge Magic Graph. SUT Journal of Mathematics 2. p105.

5. GallianA., Joseph. 2007. A Dynamic Survey of Graph Labelling-Tenth Edition. University of Minnesota, Duluth.

6. Hussain, M., Baskoro, E.T., dan Slamin, 2009. On Super Edge Magic Total Labeling of Banana Trees. Utilitas Math. Vol. 79, pp. 243-251.

7. Imron C, Setiyono B, Simanjutak R, Baskoto ET, 2007. Critical Set of Caterpillar Graph for Secret Sharing Scheme, ITB Bandung.

8. Triyani, Nurshiami, S.R, Mutia, N.E. 2013. Aplikasi Himpunan Kritis pada Pelabelan Graf Caterpillar Teratur $C_{4 n}$, Jurnal Matematika Integratif, Vol 9, No. 1, April 2013, pp 53-60.

9. Triyani, Nurshiami, S.R., 2015. Super Edge Magic Total Labeling and Its Dual Labeling on Firecracker Graph, Far East Journal of mathematical Sciences, Vol. 98, Number 3, pp. 281292. 
Triyani et al/ JMI Vol. 12 No. 1, April 2016 pp. 51-58 